\title{
El fetichismo y la idealización como mecanismos de recuperación de goce en la puesta en escena masoquista. Consideraciones psicopatológicas a partir del diálogo Lacan-Deleuze*1
}

Fetishism and idealization as jouissance recovery mechanisms in masochistic staging. Psychopathologic considerations based on the LacanDeleuze dialogue

Felipe Diaz Peña*2

Este artículo pretende hacer una reflexión psicopatológica preliminar de la perversión masoquista a partir de las lecturas de Jacques Lacan y de Gilles Deleuze. Para ello, se asume la premisa lacaniana de que el sujeto perverso busca interrogar y recuperar la porción de goce sustraída para dar lugar a un sujeto. Luego, se intenta dar cuenta de esta premisa retomando dos aspectos fundamentales de la puesta en escena masoquista descrita por Deleuze: el fetichismo y la idealización. Para finalizar, se propone que ambos mecanismos, con el fin de cumplir tal empresa, procuran la producción de un objeto positivo en la puesta en escena masoquista.

Palabras clave: Masoquismo, fetichismo, idealización, goce

*1 El presente artículo está basado en algunas articulaciones teóricas que el autor desarrolló en su tesis de Master 1 Psicología "Quelques remarques sur le concept psychanalytique de masochisme pour aborder la subjectivation et le lien social contemporains. Observations à partir du sujet, de l'objet et de l'idéal' en la Universidad París 7 - Paris Diderot el año 2019.

*2 Universidad de París (Ex-Universidad Paris - Paris Diderot). (Paris, 


\section{Introducción}

Desde los albores del psicoanálisis, el problema del masoquismo no ha estado exento de obstáculos, dudas, torpezas y cuestionamientos profundos a la teoría psicoanalítica. En sus escritos metapsicológicos, Freud (1914/2013c) procuró ejemplificar dos de los destinos pulsionales definidos por él - el trastorno hacia lo contrario y la vuelta hacia la propia persona - a partir de la transformación del componente sádico de la pulsión en masoquismo vía identificación. Más adelante, Freud (1920/2013d) definió la pulsión de muerte como aquella tendencia que procura la vuelta del organismo a un estado anterior, a lo inorgánico. Esta tendencia originaria llevó a Freud a imaginar una forma de masoquismo primario u originario que fuese anterior a las manifestaciones sádicas del sujeto. Algunos años más tarde, en su artículo El problema económico del masoquismo, Freud (1924/2013f) definió 3 formas de masoquismo: femenino, erógeno y moral. De estas 3 formas, el masoquismo erógeno o primordial consolidaría un cambio profundo en la doctrina freudiana.

En Pulsión y destinos de pulsión (Freud, 1914/2013c), apreciamos claramente que el masoquismo y el sadismo estarían puestos en una relación directa de oposición y equivalencia; perspectiva que se mantendrá a lo largo de toda la obra freudiana. Dicha concepción de estas perversiones se asienta, sin lugar a dudas, en las definiciones hechas por Krafft-Ebing (1895) en su obra Psychopathia Sexualis. Allí, se señala de entrada que el masoquismo es el contrario del sadismo. "Mientras el último es el deseo de causar dolor y usar la fuerza, el primero es el deseo de sufrir dolor y de ser sometido por la fuerza" (p. 131). Categoría acuñada en el corazón de aquello que Foucault (1976) llamó la scientia sexuales y que no carece de este aspecto confuso y poco claro propio del empirismo de esta empresa moderna (Assoun, 2003). Se forma así la problemática categoría de "sadomasoquismo" en la que sadismo y masoquismo serían polos opuestos y complementarios. Esta categoría podemos encontrarla en diferentes textos psicoanalíticos contemporáneos como si ella fuese evidente, persistiendo la falta de nitidez de la 


\section{ARTIGOS}

sexología decimonónica - léase, por ejemplo, el libro The clinical problem of masochism (Holtzman \& Kulish, 2012).

Sin embargo, este orden de ideas sobre el masoquismo no quedará establecido al interior de la tradición analítica sin dificultades y cuestionamientos importantes. Un psicoanalista que a lo largo de toda su obra no dejó de hablar de perversión y de abordar los nudos conflictivos que surgían a propósito de este tema es Jacques Lacan. Este tratamiento riguroso y sistemático de ambas perversiones llevará a Lacan a establecer algunas críticas que rompen con las señaladas concepciones sobre masoquismo y sadismo. En el curso de su seminario sobre La angustia - en el que profundizará notablemente sobre la cuestión del masoquismo - Lacan (1962-63/2005a) se referirá con tono irónico a la clasificación freudiana del masoquismo erógeno, femenino y moral diciendo: "Eso genera un poco el efecto como si dijese: está este vaso, está la fe cristiana y está la caída de Wall Street [...] Si el término de masoquismo puede tener algún sentido, convendría encontrar una fórmula que fuese más unitaria" (p. 121).

Así, Lacan criticará fuertemente los desarrollos psicoanalíticos de sus colegas contemporáneos sobre el masoquismo y felicitará la intervención de un autor que, sin hacer parte de este campo, establecerá de manera clara y rigurosa los diferentes elementos que configuran el escenario que el masoquista procura montar para asegurar su satisfacción: Gilles Deleuze. Lacan (1968-69/2006) subraya que el texto de Deleuze viene a "[...] compensar la imbecilidad estremecedora que reina en el psicoanálisis" (p. 134).

En su artículo Presentación de Sacher-Masoch, Deleuze (1967) romperá con las nosografías psiquiátricas y psicoanalíticas que procuran hacer del sadismo y del masoquismo una entidad conjunta. Por el contrario, Deleuze propondrá que ambas perversiones, nacidas a partir de la invención de un nuevo proyecto literario, deben ser consideradas separadamente a partir de una lógica que es inherente a cada una de ellas. Durante su enseñanza, Lacan señalará que el sádico y el masoquista se diferenciarían por el tipo de relación que establecen con el Otro. En ambos casos, el propósito es recuperar aquel goce perdido estructuralmente mediante la denegación de esta pérdida. Sin embargo, los medios que ocuparán uno y otro para llevar a cabo tal empresa diferirán considerablemente, y la posición respecto al Otro no será en absoluto la misma (Lacan, 1966-67/2005b; 1968-69/2006). A esto habría que articular el fino estudio de Deleuze sobre los diferentes mecanismos y elementos estéticos de los que se vale el masoquista para montar su teatro perverso. 
El objetivo del presente texto es articular las contribuciones teóricas y psicopatológicas de Deleuze y Lacan para delimitar algunos de los elementos que serían propios de la estructura masoquista perversa. Así, para realizar esta tarea, procuraremos definir los diferentes aspectos que pueden ser apreciados en la empresa masoquista: su relación al Otro y al goce perdido, el tipo de escena que éste monta a partir del fetiche y la idealización, las operaciones psíquicas que están a la base del fetichismo y la idealización masoquista y de qué manera éstas se articulan en el fantasma masoquista para procurar el surgimiento real de un objeto que permita esta recuperación de goce.

\section{Una consideración estructural: el masoquista interroga la sustracción de goce que da lugar al sujeto}

En la lección del 16 de enero de 1963, Lacan (1962-63/2005a) señala que la meta declarada del masoquista es encarnarse él mismo como objeto a desechar, volverse un perro bajo la mesa del comedor, un objeto de intercambio que puede ser puesto en circulación dentro del mercado junto con otros objetos. En un pasaje de la novela La venus de las pieles, Séverin y Wanda acuerdan un contrato que reglamenta la relación entre ellos. Al momento de discutir las condiciones del contrato Wanda dice a su contraparte: "Imagina un poco que ahora, prácticamente, no vales más que un perro o un objeto. Eres mi cosa, el juguete que puedo destrozar si ello me procura un momento de placer" (Sacher-Masoch, 1967). La empresa del masoquista remite a esta tarea imposible de reconocerse como lo que es, como objeto $a$. Sin embargo, no podemos permitirnos quedar satisfechos con esta explicación si no nos interrogamos por las implicancias subjetivas de esta empresa. ¿Qué quiere decir reconocerse como objeto $a$ ? Para responder a esta pregunta debemos dar un paso hacia atrás y aclarar el lugar que ocupa el objeto $a$ dentro del proceso de constitución subjetiva.

El proceso de constitución subjetiva implica que el sujeto surge a partir de su encuentro con la cadena significante y el objeto $a$ da cuenta de aquella falla estructural que testimonia de este encuentro del sujeto con el Otro. Dicho de otro modo, el sujeto no existe sino a partir de la incidencia del significante en un cuerpo real, encuentro que produce una necesaria sustracción de goce para dar lugar a un ser hablante. Una de las maneras en las que Lacan (1962$-63 / 2005 a)$ procuró hacer patente esta operación es a través del esquema de la 


\section{ARTIGOS}

división; nosotros nos serviremos de la última de sus versiones que figuran en el seminario sobre La angustia. (Véase la Figura 1)

Figura 1

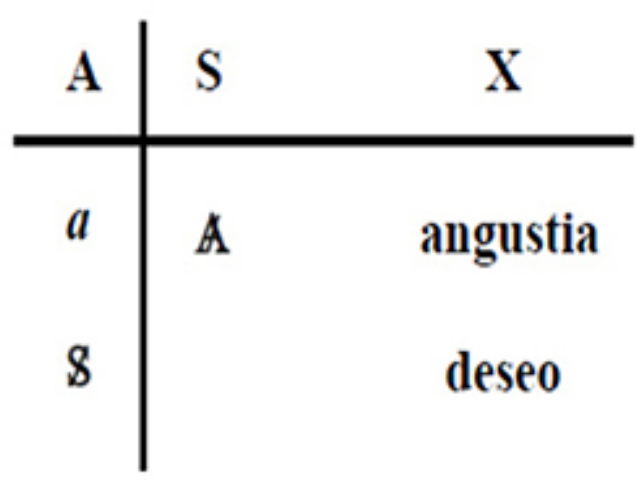

La S mayúscula que se sitúa al comienzo de la operación representa un sujeto hipotético, un sujeto mítico que no estaría atravesado por la tachadura provocada por el significante. No obstante, el sujeto no existe sino a partir del significante que le es anterior, que le es constituyente y es en este encuentro con el Otro, el tesoro de los significantes, que va a interrogarse de la siguiente manera: "En A, ¿Cuántas veces cabe S?" (Lacan, 1962-63/2005a, p. 211). Desde esta operación, el cuerpo que ha de advenir sujeto debe renunciar a un trozo real de sí mismo para inscribirse en el orden simbólico, dando lugar a aquella marca de lo irreductible para el sujeto: el objeto pequeño $a$ como lo "irreductible en esta operación total de advenimiento del sujeto en el lugar del Otro" (Lacan, 1962-63/2005a, p. 211). Este objeto se desprende, cae de esta operación subjetiva, es el desecho que queda luego de la fundación del sujeto el cual marca la relación de éste con el deseo y con la angustia. Respecto a esto, Pablo Reyes (2015) precisa que esta versión del esquema de la división "supone que antes del advenimiento del sujeto tachado existe un momento de angustia que indica el momento constitutivo del objeto pequeño $a$ " (p. 247). La producción de este objeto implica una pérdida que, para Lacan, es irreductible al significante. Es un corte que se hace sobre un trozo del cuerpo el cual evoca una pérdida irreparable para el sujeto; cisura anterior a toda constitución de la imagen narcisista (Reyes, 2015). La pérdida de este objeto permitirá el advenimiento del ser hablante y la articulación de su relación al deseo mediatizada por el falo $(-\varphi)$ y soportada por el fantasma. 
Los tres pisos que se aprecian en el esquema, corresponden a tres tiempos diferentes de la operación que hemos evocado. El piso de arriba remite al tiempo del goce, el siguiente remite al tiempo de la angustia, y el piso de abajo remite al tiempo del deseo. Al final de esta operación, $a$ tomaría una función de metáfora del sujeto del goce, es decir, de aquel sujeto mítico situado en el piso de más arriba.

Es por ello que $a$ simboliza lo que, en la esfera del significante, se presenta siempre como perdido, como aquello que resiste a la significantización. Ahora bien, es justamente este desecho, esta caída, esto que resiste a la significantización, lo que constituye el fundamento como tal del sujeto deseante, ya no del sujeto del goce [...]. (Lacan, 1962-63/2005a, p. 226)

Ahora bien, para retomar el caso del masoquista, diremos que éste, al intentar reducirse a la posición de objeto de desecho, busca reencontrarse en aquel tiempo de angustia suscitado por el surgimiento del objeto a. El masoquista construirá todo un escenario en el cual intentará identificarse a este resto irreductible de la constitución del sujeto con lo que se procura una respuesta a la pérdida de este objeto. Al tomar el lugar de este objeto de desecho, el masoquista evoca un momento primordial en que la aparición de este objeto procura la articulación de un sujeto; tal como lo señala Assoun (2003) "el masoquista erige su objeto en "sujeto"" (p. 26). A este respecto, Lacan (1962-63/2005a) precisa: "el masoquismo toma en esta perspectiva el valor y la función de hacer aparecer y de hacer aparecer claramente [...] cuando el deseo y la ley se encuentran juntos, puesto que lo que el masoquista intenta hacer aparecer es algo donde el deseo del Otro hace la ley" (p. 122). De este modo, el masoquista busca reencontrar en el Otro un momento primordial en el que el deseo y la ley son una sola y la misma cosa.

En este momento podemos permitirnos avanzar un paso. Proponemos que lo que la escena masoquista intentaría evocar es el momento mítico en que el sujeto está sometido a la ley encarnada del Otro y que Lacan define en su seminario sobre Las formaciones del inconsciente como el primero de los tiempos lógicos del Edipo. En un primer momento, el infans está completamente a la merced del deseo materno. La palabra de la madre impone desde el principio un tipo de ley al infans que lo introduce en la estructura significante. No obstante, ésta es una ley descontrolada que depende enteramente del sujeto que la soporta. En dicho seminario, Lacan (1957-58/1998) utilizará un neologismo para referirse a esta situación; señala que 


\section{ARTIGOS}

el infans es "un assujet, ${ }^{1}$ puesto que se experimenta y se siente primero como profundamente sometido al capricho del que depende, incluso si este capricho es un capricho articulado" (p. 189). Podemos proponer que aquello a lo que el masoquista apunta es a reencontrar aquel Otro que lo somete a la ley de su puro capricho y que lo remite a un momento primordial en el encuentro del sujeto con el significante.

Al reinstalar una escena que remite a un tiempo reprimido en el sujeto, el masoquista suscita angustia en su partenaire, pone en primer plano aquel lazo íntimo y sensible, tejido entre el objeto y la angustia, y que nosotros identificamos en el piso de en medio del esquema de la división. En el libro autobiográfico Confesión de mi Vida, Wanda de Sacher-Masoch (1989) relata cómo se vio forzada a infligir torturas físicas y morales a su marido, el caballero de Sacher-Masoch. "Este abismo oscuro de sufrimiento y de tortura expresaba para él la dicha más grande y embriagante [...] Yo no tenía ninguna experiencia en esta materia; lo tomaba como locura y estaba a punto de sacarme de quicio" (p. 128).

Que el perverso busque la angustia del Otro es un discurso recurrente al interior del campo psicoanalítico, pero una pregunta que nos permitiría precisar el obrar del perverso y del masoquista en particular es ¿Por qué el masoquista busca la angustia del Otro? En su seminario sobre La lógica del fantasma, Lacan (1966-67/2005b) señala que la constitución del sujeto como efecto de su encuentro con el significante produce una disyunción fundamental entre el cuerpo y el goce: es la función del sujeto. La pérdida de este objeto limpia el exceso de goce del cuerpo y permite el advenimiento del sujeto del inconsciente, he ahí lo que representa la barra que tacha al sujeto, marcando así el fin de la operación de la división. El objeto $a$ operará como metáfora de aquel sujeto mítico del goce. Es el significante fálico, en tanto que negativizado, y por ende inaprehensible, el que, para el neurótico, simbolizará esta sustracción de goce. Lacan (1966-67/2005b) puntualiza a este respecto: "esta función de sujeto [...] tiene por efecto la disyunción del cuerpo y del goce y es ahí, el nivel de esa separación, que la perversión interviene típicamente" (p. 437). El perverso procurará reunir el cuerpo y el goce. El perverso no produciría una metáfora de este goce primordial,

\footnotetext{
${ }^{1}$ Neologismo que surge de la combinación de dos palabras en francés: sujet (sujeto) y assujetti (sometido). Así, el assujet es un a-sujeto, un no-sujeto en la medida que está sometido a la demanda aplastante del Otro.
} 
sino que procura reencontrarlo en lo real del cuerpo del partenaire, y más precisamente, en un trozo del cuerpo del partenaire. Si el objeto $a$ constituye una metáfora del goce perdido, el perverso procura hacer surgir un objeto en el Otro para que este goce le sea restituido; tiempo de la angustia en el segundo piso del esquema de la división que termina imponiendo la barra en el sujeto y en el Otro.

En su seminario De un Otro al otro, Lacan (1968-69/2006) precisará esta relación del masoquista al objeto. En la acción del masoquista, éste organiza las cosas de tal forma que se encuentra a sí mismo desprovisto del acceso a la palabra e imposibilitado de cualquier dialéctica. En la identificación del masoquista al objeto de desecho, éste procura montar una escena en la que pueda procurarse el surgimiento de un objeto pulsional: la voz.

Que el masoquista haga de la voz del Otro, sólo para él, el garante frente al cual responderá como un perro, es lo esencial de la cosa. Ello se aclara por esto, éste va precisamente a buscar un tipo de Otro que pueda ser puesto en cuestión respecto a este punto de la voz, la querida madre, por ejemplo, como lo ilustra Deleuze, con la voz fría y recorrida por todas las corrientes de lo arbitrario. (p. 257)

De este modo, el masoquista procura hacer de su partenaire un Otro absoluto no concernido por la división entre enunciado y enunciación. $\mathrm{Su}$ discurso sería sólo un discurso para ser impuesto reduciéndolo a una pura demanda bruta, propia de los momentos originarios en que el infans se encuentra con la ley descontrolada de la madre.

Resulta entonces pertinente examinar algunos de los mecanismos mediante los cuales el masoquista procura esta restitución de goce en su relación al Otro y que fueron brillantemente aislados por Deleuze.

\section{El fetiche y el enamoramiento: dos fenómenos cruciales para el escenario masoquista}

\section{El fetichismo: fijación y congelamiento}

En su amplio tratado sobre las perversiones sexuales, Krafft-Ebing da cuenta de la cercanía que existiría entre masoquismo y fetichismo al punto que habría un estado intermedio entre estas dos perversiones; el fetichismo de pies sería, a su vez, un masoquismo larvado. Krafft-Ebing (1895) propone que 


\section{ARTIGOS}

es muy probable que los fetichistas de pies y zapatos tienen un masoquismo basal más o menos consciente. No resulta difícil de aceptar esta hipótesis si vemos la cercanía entre la adoración del pie y del zapato y la voluntad de dejarse pisotear, tanto literal como metafóricamente. Por lo demás, el mismo Krafft-Ebing señala: "en la mayor parte de casos de masoquismo, recibir golpes de pie es la principal forma de expresión de la servidumbre” (p. 162). Así, el empeño de Krafft-Ebing busca mostrar, a partir de viñetas clínicas publicadas por sus colegas, que en el adorador de zapatos habría une suerte de punto límite que reúne a ambas perversiones.

$\mathrm{Si}$ retomamos la vasta obra literaria de Masoch veremos que la relación fetichista con los abrigos y chaquetas de pieles es una constante que reencontramos en una gran parte de sus relatos e incluso en su propia biografía. Podemos observar en numerosos pasajes de La Venus de las Pieles el gusto y la idolatría de Severino, el protagonista, por las mujeres vestidas con abrigos de piel. Severino cuenta a su amada el momento primordial en que su búsqueda por la voluptuosidad habría nacido de un encuentro en que es sometido y golpeado por su tía. Al terminar aquel relato, éste dice "mi gusto por las mujeres se despertó bajo la vara de una bella criatura voluptuosa que, en su abrigo de pieles, me pareció una reina en cólera: a partir de este día, mi tía pareciome la mujer más encantadora que Dios haya puesto en la tierra" (Sacher-Masoch, 1967, p. 150). Del mismo modo, cuando ambos protagonistas realizan la firma del contrato que hará de Severino el esclavo de su dómina, la cláusula final especifica que, a cambio, "la Señora von Dunajew promete, en tanto que su ama, mostrarse tantas veces como sea posible en pieles, particularmente cuando ésta será cruel con su esclavo" (p. 195). Este mismo fetiche es también testimoniado en el libro autobiográfico de una de las encarnaciones de la venus de las pieles en la vida del escritor: Wanda de Sacher-Masoch (1967). Allí, ella indica "siempre debía vestirme con pieles, por supuesto; en la ausencia de pieles los placeres de Leopold estaban desprovistos de sabor" (p. 31).

Freud (1927/2013g) retoma el problema del fetichismo para dar cuenta del mecanismo inconsciente que operaría en la instalación del fetiche. El pequeño varón habría renunciado a aceptar una percepción tan patente como traumatizante: la ausencia de pene en la mujer y, muy particularmente, en el cuerpo su madre. Para defenderse de esta percepción, el niño erige un objeto o un miembro del cuerpo como sustituto del falo materno. Así la representación de la ausencia caería bajo la acción de la desmentida (Verleugnung) la cual implica una enérgica acción del infante. Sin embargo, esta creencia en el 
falo materno no logra perdurar a cabalidad, he allí la particularidad de la desmentida. Esta representación es reconocida y negada al mismo tiempo, "[...] se ha llegado a un compromiso como sólo es posible bajo el imperio de las leyes del pensamiento inconsciente [...] Sí; en lo psíquico la mujer sigue teniendo un pene, pero este pene ya no es lo mismo que antes era. Algo otro lo ha reemplazado" (p. 149). Así, le fetiche se erige como un monumento a la castración que la reconoce y desconoce al mismo tiempo.

Conjuntamente a ello, Freud (1927/2013g) agrega que la instauración del fetiche sería, más bien, la suspensión de un proceso, la detención de la cadena de representaciones en el momento inmediatamente anterior a la impresión traumática. Los objetos que se suelen tomar como fetiches tales como los zapatos, las prendas íntimas o las pieles no son sino aquellos que rodean la escena de tan complejo descubrimiento. Este permitiría vencer la amenaza de castración, haciendo de la mujer un objeto sexual soportable para el fetichista.

Siguiendo el argumento freudiano, Deleuze (1967) ahonda en el lugar del fetiche para dar cuenta de su rol en el escenario masoquista. Para Deleuze el fetiche es denegación, neutralización defensiva y neutralización idealizante. Denegación en el sentido de la desmentida de la ausencia de pene en la mujer; neutralización defensiva en la medida que el conocimiento de la situación persiste, pero al mismo tiempo queda suspendido en "el último momento en el que aún se podía creer" (p. 29); neutralización idealizante en la medida que la creencia en el falo femenino lleva a un proceso de ensalzamiento que contrarresta aquellos aspectos molestos de la realidad. De este modo, para Deleuze, "el fetiche no sería entonces, de ningún modo, un símbolo, sino más bien un plano fijo y congelado, una imagen detenida, una foto a la cual se vuelve siempre para conjurar [...] los desagradables descubrimientos de una exploración" (p. 29).

Esta triada que se articula a partir del emplazamiento del fetiche pertenecería esencialmente al masoquismo; para Deleuze no habría masoquismo sin un fetichismo anterior. La denegación, el suspenso y la idealización hacen parte de una constelación masoquista que pretende la conformación de una mujer ideal (Deleuze, 1967), mujeres de mármol y piedra cuyo movimiento queda congelado por los procesos que subyacen a la instalación del fetiche. Se trataría de una mujer que queda identificada a una estatua, a un retrato o a una foto que pone al sujeto masoquista al abrigo de confrontarse con la falta en el Otro; suspenso e idealización como ardides para eludir la incompletud que da lugar al deseo. 


\section{ARTIGOS}

\section{Idealización y enamoramiento en el masoquismo}

Para Deleuze, este proceso de idealización logra plasmarse en lo que Sacher-Masoch llama "el suprasensualismo", doctrina filosófica sobre el amor que es desarrollada a cabalidad en una breve novela que no por casualidad lleva por nombre El amor de Platón. En ella, el protagonista define en diferentes ocasiones su concepción suprasensual del amor: "Para mí, el amor es ante todo un don espiritual de sí a otra persona. Uno da su alma a cambio de un alma" (Sacher-Masoch, 1991b, p. 32). Este amor suprasensual excluye todo intercambio sexual, todo encuentro debe mantenerse en un ámbito estrictamente espiritual, y con ello se da lugar a lo que, en la constelación fantasmática del masoquista, Deleuze (1967) llama un hombre nuevo sin sexualidad; "evitaba todo contacto con el sexo, era suprasensual hasta la demencia" (Sacher-Masoch, 1967, p. 149) expresa el protagonista de La venus de las pieles. Este proceso e idealización llega al punto de que el ideal del masoquista será encarnado por una de sus mujeres amadas.

No ha de extrañarnos entonces que esta encarnación del ideal se encuentre de forma explícita en las palabras de los diferentes protagonistas de Sacher-Masoch. La ama de Severino llega a decir: "tú lo sabes bien [...] soy una mujer de piedra, la Venus de las pieles, tu ideal. Arrodíllate y adórame" (p. 231). Proponemos que este proceso de encarnación del ideal en la puesta en escena del masoquista puede ser abordado a partir de un fenómeno que también fuera aislado por Freud y que, al menos en el caso específico del masoquismo, se articularía a la desmentida: el enamoramiento (Verliebtheit). Esta operación ocuparía un lugar importante en las perversiones instalándose allí donde el ideal del yo no ha podido ocupar un lugar estrictamente simbólico, sino que, precisamente, es encarnado por otro degradándolo a su mera función imaginaria. Freud (1914/2013b) señala que "el enamoramiento consiste en un desborde de la libido yoica sobre el objeto. Tiene la virtud de cancelar las represiones y de restablecer las perversiones. Eleva al objeto sexual a ideal sexual" (p. 97). Los desarrollos de Freud a partir de su concepto de narcisismo lo llevarán a que, en 1921, en "Psicología de las masas y análisis del yo", logre una de las definiciones más acabadas y complejas del fenómeno del enamoramiento cuyas manifestaciones parecen distar muy poco de la fantasmática masoquista. En el enamoramiento se produce un fenómeno de sobrestimación del objeto sexual, dicho objeto no se ve afectado por las críticas; proceso que se produce, precisamente, mediante la cancelación de las aspiraciones sensuales en razón de una admiración "celestial" o, si se quiere

Rev. Latinoam. Psicopat. Fund., São Paulo, 24(3), 537-559, set. 2021 
"suprasensual". Resulta evidente la cercanía entre la puesta en escena del masoquismo y el fenómeno de enamoramiento tal como es descrito por Freud (1921/2013e): "rasgos de humillación, restricción del narcisismo, perjuicio de sí, están presentes en todos los casos de enamoramiento; en los extremos, no hacen más que intensificarse $\mathrm{y}$, por relegamiento de las pretensiones sensuales, ejercen una dominación exclusiva" (p. 107)

Esta cercanía no puede dejarnos indiferentes y resulta entonces necesario adentrarnos en este fenómeno si queremos abordar de forma rigurosa el problema de la perversión masoquista. El problema de la disociación del amor celestial y del amor sensual fue ampliamente tratada algunos años antes por Freud (1912/2013a) en su texto Sobre la más generalizada degradación de la vida amorosa. Ya en ese entonces, Freud daba cuenta de una escisión en la vida amorosa masculina que se resume de forma brillante en la frase "cuando aman no anhelan, y cuando anhelan no pueden amar" (p. 176). De este modo, la sensualidad queda completamente alejada de los objetos amados en la medida que reenvían a un sujeto incestuoso primordial. En el caso del enamoramiento, este proceso sería llevado al extremo, pero pareciera mantenerse en la misma línea de la sexualidad masculina. No ha de resultar azaroso entonces que Paul Laurent Assoun (2003) se refiera al masoquismo como una "parodia del amor", una exageración del sometimiento sexual que está a la base del amor cortés. “El masoquista es este 'caballero blanco' fanático, que instituye a la Dama y a su reino para volverse su único esclavo. En esta búsqueda de la 'dominatriz', el masoquista se legitima de este culto a la Domina" (p. 37).

"El afán que aquí falsea el juicio (en el enamoramiento) es el de la idealización" (Freud, 1921/2013e, p. 106). Freud, al procurar dar cuenta de los mecanismos a partir de los cuales se conforma una masa, pone en relación el enamoramiento con la hipnosis y, evidentemente, con la formación de la masa. De ellos señala que la hipnosis no se diferencia de la masa más que por el número, mientras que la masa difiere del enamoramiento por la cancelación absoluta de aspiraciones sensuales. No creemos poder aventurar que en todo masoquista hay una cancelación total de la aspiración sensual - después de todo el caballero de Sacher-Masoch tuvo hijos - y es justamente ello lo que nos permite decir que el enamoramiento jugaría un rol fundamental en el teatro masoquista. Esta cercanía entre masa, hipnosis y enamoramiento, también se pone en juego en la disposición fantasmática masoquista tal como lo muestra otra novela de Sacher-Masoch (1991a), La madre de Dios. La secta es un tópico recurrente en la literatura de Masoch y La madre de Dios es, junto con La pescadora de almas, uno de los puntos más acabados 


\section{ARTIGOS}

en lo que refiere al abordaje de esta temática. En ella se aprecia cómo el enamoramiento se pone en juego en la relación del protagonista con Mardona, la madre de Dios; líder de una secta agrícola de las estepas austro-húngaras. Lógrese entonces también observar cómo el límite entre enamoramiento, hipnosis y conformación de la masa se difumina en el fantasma masoquista. Así, para referirse a ella y su secta, uno de sus personajes refiere: "parece que ejerce una influencia sobre estos hombres... ¡Una verdadera encantadora! Y hay que confesarlo porque es verdad... parece que ya ha hecho milagros" (Sacher-Masoch, 1991a, p. 53). Esta influencia que ejercería la mujer del masoquista forma parte de su teatro encarnado que intenta erigir a un Otro en que encuentra la identidad brutal del deseo y la ley, dos elementos que, para el neurótico, suelen mostrarse separados gracias la represión fundamental del objeto pulsional (Lacan, 1962/1999b); he allí el motivo de búsqueda de esta influencia que el masoquista busca con impertérrita obediencia y sumisión. Assoun (2003) se refiere al masoquista como aquel que hace órdenes de los deseos del Otro. Así, éste procura reencontrar en su partenaire la dimensión primordial del puro capricho que Lacan (1957-58/1998) identifica al primer tiempo lógico del Edipo.

El masoquista establece así una alianza con este partenaire de tan particulares características. Se trata de una alianza que permite erigir una mujer "a la que no le faltaría nada" (Deleuze, 1967, p. 60). Fetichismo e idealización como elementos fundamentales para la puesta en juego de la obra de teatro masoquista; desmentida y enamoramiento como dos operaciones que se articulan para poder tener éxito en esta empresa de recuperación del goce arrebatado en el momento de la constitución subjetiva. El masoquista formula una respuesta estereotipada y fija a la pregunta "¿Qué quiere el Otro de mí?” mediante una articulación compleja de elementos fantasmáticos que se exteriorizan bajo la forma de esta pieza teatral que éste busca montar - encuéntrese allí, probablemente, una de las diferencias fundamentales entre el masoquismo perverso y el masoquismo del neurótico. Todo este procedimiento procura establecer una relación tan segura como sea posible con el Otro desembocando en este culto con ribetes místicos a la figura de la mujer que encontramos en la literatura masoquista, constituyendo así uno de los aspectos fundamentalmente propios del masoquismo y esencialmente distintos del sadismo.

En la obra de Masoch, palabras de orden y descripciones se sobrepasan también hacia una más alta función, mítica o dialéctica; esta función descansa sobre el conjunto de la denegación como proceso reactivo y sobre el suspenso como Ideal de la imaginación pura. (Deleuze, 1967, p. 32) 
Así, tanto el fetichismo como la idealización que se ponen en juego en estos dos mecanismos de desmentida y enamoramiento quienes constituyen dos elementos fantasmáticos centrales en el montaje del teatro masoquista.

\section{El objeto a en el teatro masoquista: recuperación de goce por medio del fetichismo y la idealización}

Si la desmentida y el enamoramiento dentro de la fantasmática del masoquista ameritan este análisis, ello es en virtud de la forma ejemplar en que estos procesos nos muestran un aspecto esencial de la empresa perversa: la tentativa de recuperación de aquel goce que fue sustraído para que la función del sujeto tenga lugar. Esta restitución de aquello esencialmente perdido procura lograrse a través del surgimiento en la escena perversa de aquel objeto que fue primordialmente desechado en el encuentro con el Otro y cuya metáfora está dada por aquello que Jacques Lacan definió como objeto $a$. Así, tanto el fetichismo como la idealización masoquista, mediante las operaciones de desmentida y enamoramiento, procuran hacer surgir este objeto en la teatralización del fantasma que el perverso exige una y otra vez.

Comencemos entonces por el fetichismo y la operación que está a la base de este: la desmentida. Freud (1927/2013g) especifica que el fetiche vuelve a la mujer un objeto sexual soportable, pero esta aseveración debe ser precisada. El fetiche no sólo permite que la mujer se vuelva un objeto sexual soportable, sino que se instala como una condición imperativa para el deseo que permitiría una relación segura con el encuentro sexual. Ello en la medida que se materializaría aquello que es inaprehensible en la experiencia deseante mediante la fijación y el congelamiento a un significante específico, deteniendo la metonimia de la cadena. Si el fetiche está presente en la escena, no existen inconvenientes para el encuentro sexual; "Lo que otros varones requieren y deben empeñarse en conseguir, no depara al fetichista trabajo alguno" (p. 149).

Lacan (1956-57/1994) señala que el problema del fetiche muestra de forma particularmente aguda la relación del sujeto con el objeto. Siguiendo la línea freudiana, Lacan hace hincapié en el hecho de que, si el fetiche representa el pene, éste no es cualquier pene, sino el pene en tanto aquello de lo que la mujer carece. Pero, de lo que se trataría aquí no es del órgano peniano en sí, sino del falo como significante que se presenta como ausencia en el intercambio y a partir del cual se instala la diferenciación simbólica de los sexos. Al igual que Freud, y del mismo modo que Deleuze lo hará posteriormente, Lacan (1956-57/1994) subraya este aspecto del fetiche que 


\section{ARTIGOS}

remite a una película detenida, a un momento en el que la historia se congela justo antes de descubrir la presencia-ausencia en el cuerpo de la madre.

Lacan nos aporta una sutileza clínica respecto al fetiche de valor incalculable para abordar el caso del masoquista: la diferencia entre el zapato y el abrigo. Si bien, en ambos casos se trata de nosografías que pertenecen al fetiche, el rol que ocupa cada uno de estos objetos no es exactamente el mismo. Habría una suerte de continuidad entre dos polos: el fetichismo del zapato y el travestismo en el que el fetiche de las vestimentas se situaría en un lugar de transición. El fetiche de las prendas, a diferencia del zapato, no apunta tanto a una materialización efectiva del objeto que se escondería detrás del velo, sino que más bien constituiría una suerte de égida para quien lo porta (Lacan, 1956-57/1994). Los pesados abrigos de pieles que portan las heroínas de Masoch son una protección contra los riesgos del frío, conservando así su función utilitaria (Deleuze, 1967). En los últimos encuentros entre Severino y su mujer-verdugo, éste señala lo que le evoca un cuadro que su idolatrada habría mandado a pintar:

Imagino a la Diosa del amor descendida del Olimpo hacia un mortal, la imagino envolviendo su cuerpo sublime en una grande y pesada piel para no morir de frío en nuestra tierra moderna. Intenta calentar sus pies en el pecho del bienamado; imagino al favorito de una bella déspota que latiguea a sus esclavos cuando está cansada de besarlo, y que es tanto más locamente amada por él cuando ella lo rechaza a patadas. Llamaría a este cuadro: "La Venus de las pieles". (Sacher-Masoch, 1967, pp. 219-220)

Este breve pasaje de La Venus de las pieles nos permite observar la doble dimensión que presentaría el fetiche par Lacan: por una parte, la fusta como aquel significante que viene a positivar la ausencia de un índice efectivo para el deseo, siendo el fetiche "la cáscara, el borde, la franja, el perifollo, la cosa que oculta, que se sostiene a partir de que nada es más designado para la función de significante del el deseo del Otro" (Lacan, 1958-59/2013, p. 564). Por otra parte, el fetiche de los abrigos de piel cumple aquella función protectora de la madre y que garantiza también el placer en la puesta en escena del masoquista, tal como lo señalaba la esposa del escritor.

$\mathrm{Si}$ el fetiche permite conjurar la penosa ausencia de un significante aprehensible y concreto para el deseo del Otro, congelar los peligros del movimiento justo en aquel momento en que todavía se podía creer y acceder una satisfacción sexual que no demandaría esfuerzo alguno, ello se debe a que el fetiche encarna aquel objeto que se sustrae irremediablemente en la experiencia del neurótico. Es el objeto causa-de-deseo que Lacan designó 
como objeto $a$. El fetiche ilustra su estatuto de objeto-causa en tanto "que no es el zapatito, ni el seno, ni lo que sea que venga a encarnar el fetiche lo que es deseado" (Lacan, 1962-63/2005a, p. 118). Basta solamente que el fetiche se encuentre dentro de la escena para que éste pueda garantizar la satisfacción sexual. Así el fetiche es un objeto que viene a positivizar, materializar y encarnar algo que se encontraría ultra condensado en él. Vemos entonces, gracias a la fantasmática del masoquista, que las funciones del fetiche son múltiples y aquello que porta en sí es lo suficientemente potente como para detener toda cadena de representaciones, anular todo movimiento, y conjurar los riesgos de la hendidura hasta el punto de reducirla a un pequeño objeto positivo y manipulable. ¿Qué es lo que se aglomera en la fusta de la mujerverdugo, en sus zapatos de tacón o en las sofocantes pieles? Puesto que hemos tomado la vía lacaniana, respondemos: goce. Bien vimos que el masoquista monta todo su teatro con el fin de producir un objeto específico, un objeto que surge allí en lo real de la escena que éste arma para así poder capturar y recuperar esta porción de goce sustraída por la pérdida del objeto. El fetiche, que opera a partir de la desmentida, es entonces una de las vías que toma el masoquista para poder recuperar este goce perdido mediante la instalación de este objeto que conjura la falta en el Otro. Al menos, así es como Lacan lo plantea en su seminario La lógica del fantasma al decir que es de la sustracción de un goce, cuya elección se hace por la maniobrabilidad de éste que viene a introducirse lo que él y Marx llaman "el fetiche, a saber, este valor de uso, extraído, congelado - un agujero en alguna parte - el único punto de inserción necesaria a toda ideología sexual" (Lacan, 1966-67/2005b, p. 312).

Del mismo modo, el enamoramiento también está concernido por la producción de un objeto. Freud (1921/2013e) resumía el enamoramiento mediante la fórmula "el objeto se ha puesto en el lugar del ideal del yo" (p. 107). Esta fórmula se extiende entonces para dar también cuenta del proceso de formación de una masa, siendo ésta definida por una serie de individuos que habrían puesto el mismo objeto común en el lugar de su ideal del yo. El ideal del yo participa de la constitución del sujeto en tanto está concernido por una ausencia específica: la ausencia designada por el objeto $a$ (Lacan, 1960/1999a). El ideal viene a tomar el lugar en lo simbólico que resulta de esta operación cuya consecuencia es la elisión del sujeto bajo un significante y la sustitución de la relación directa con el objeto - sustitución del goce, si se quiere - por la mediación fálica del deseo que podemos escribir así: $\frac{-\varphi}{a}$. El ideal del yo no será sino las insignias fálicas a partir de las 


\section{ARTIGOS}

cuales el sujeto podrá revestirse y adoptar una posición sexuada; las insignias del padre (Lacan, 1957-58/1998). Freud (1914/2013b) señala que, si no hay renuncia al objeto primordial sobre la cual se monta el drama edípico tampoco logra constituirse el ideal del yo, la tendencia sexual infantil reaparece en la vida adulta bajo la forma de la perversión.

El masoquista suspende su relación al ideal encarnándolo en la mujerverdugo a la cual erige; no renuncia a la presencia de este objeto, sino que la produce haciéndolo surgir en la voz de su mujer de piedra, encarnándolo en el fetiche que acompañan a su mujer de mármol. Al final de su seminario sobre Los cuatro conceptos fundamentales del psicoanálisis, Lacan (1964/1973) señala que todo análisis que tiene por objetivo la identificación del analizante con el analista está condenado a pasar por alto la distancia que existiría entre la imagen especular i $(a)$ y el objeto causa-de-deseo, produciéndose así un fin de análisis que estaría marcado por la cristalización de la sugestión antes que por la liquidación de la transferencia. Precisamente esta superposición entre yo-ideal, ideal del yo y objeto $a$ se configuraría, señala Lacan, en los estados de enamoramiento, hipnosis o masa definidos por Freud. En ellos se produce "la conjunción de $a$ con el ideal del yo" (Lacan, 1964/1973, p. 244). Se trata de la encarnación de un objeto que da consistencia en lo real a este núcleo significante del ideal del yo que Lacan definió como rasgo unario.

Si el enamoramiento tiene un lugar central en el masoquismo, esto sería porque permite una sutura en la herida narcisista propia a la constitución del sujeto, es un intento de juntar aquello que la función del sujeto separa irremediablemente: cuerpo y goce (Lacan, 1966-67/2005b), mediante esta relación dual con esta mujer-verdugo idealizada. Deleuze (1967) propone que, dentro de la fantasmática masoquista, a lo que se apunta es al nacimiento de un hombre nuevo sin sexualidad, éste es el hijo de una mujer que no está concernida por la falta; encuentro radical con la omnipotencia primordial del Otro. Agregaríamos entonces que se trata de una suspensión en la ilusión especular, en la fascinación del bebé que percibe el rasgo unario, venido del campo del Otro, entrecruzándose en el campo de la identificación primaria. Así, se desconoce la estructura que sostiene esta ilusión: el significante. Al respecto, resulta elocuente lo que señala Assoun (2003) quien indica que el masoquista se pone en escena disponiéndose en

la jeta misma del león de la castración [...] El hecho de ser sistemáticamente un perdedor no lo impide, sino que más bien lo funda, en su "mito individual", queriéndose "magnífico". Desecho real del Otro. Lo que el fantasma de 
fustigación revela es esta idea de elección mediante la punición: ella es prueba de amor. (p. 39)

Recuérdese la figura del preferido que tiene el honor de servir como objeto que abriga los pies de su amada con su pecho. El masoquista se instala como víctima triunfante del martirio.

Si las heroínas de Masoch logran un efecto en los protagonistas que no dista del estado hipnótico es porque en ellas, en su cuerpo, surge este objeto ultra condensado que captura y fascina la atención del masoquista y que no es sino una de las formas del objeto $a$ definidas por Lacan: la voz. Si la ley y el deseo se vuelven indiferentes la una de la otra es debido al surgimiento de la voz, la voz fría y arbitraria, como objeto pulsional. "Aprovecha que tienes un marido que no se opondrá a ninguno de tus caprichos, que te deja absolutamente libre" (De Sacher- Masoch, 1989, p. 96) dice el escritor a su esposa. Así, Lacan (1968-69/2006) establece que el eje de gravitación del masoquista es la restauración al Otro de este objeto perdido, entregándoselo como suplemento y que hace de él otro excepcional que sería capaz de enunciar por completo aquello que desea.

Encuéntrese entonces, en las formas del fetichismo y de la idealización, dos tácticas específicas del masoquista para alcanzar un determinado plus-de-goce.

\section{Reflexiones finales: por una psicopatología que reconozca el proyecto perverso (no sólo) masoquista}

Hemos visto que, en la puesta en escena del masoquista, el fetichismo y la idealización convocan una seria de operaciones, restricciones, formas de actuar y elementos teatrales para poder lograr una escena capaz de asegurar la satisfacción sexual del masoquista - aun si todo el fantasma masoquista procura dejar en suspenso el momento del encuentro sexual (Deleuze, 1967) - al poner en juego, en el exterior, su rígida fantasmática. Toda la empresa de la perversión masoquista apuntaría a la constitución de un universo simbólico diferente de aquel en el que se inscribe habitualmente el neurótico, es decir, aquel universo cuya inconsistencia inherente le impide - felizmente erigirse como un universal. Ya Lacan (1957-58/1998) criticó múltiples veces a sus colegas contemporáneos por pretender que la perversión sería una suerte de estado salvaje de la pulsión, la manifestación de la pulsión pura. 


\section{ARTIGOS}

Lejos de ello, señala Lacan, la perversión sería una estructura tal como lo es la neurosis con sus propios avatares y su propia relación al significante. Deleuze (1967) indica que el masoquista vive el orden simbólico como intermaternal, y plantea las condiciones bajo las cuales, en este orden, la madre terminaría confundiéndose con la ley. El masoquista pone en cuestión la metáfora paterna como elemento único para constituir un orden simbólico. "Hay lugar para sorprenderse, dice Deleuze (1967, p. 56), cuando vemos que el psicoanálisis, en sus exploraciones más avanzadas, enlaza la instalación de un orden simbólico al nombre-del-padre".

Hemos visto qué tan lejos puede ir el masoquista en sus tácticas para poner en cuestión el orden simbólico del padre, y lo mismo podríamos decir de otras tácticas que no hemos podido tratar, como el contrato o la subversión de la ley (Deleuze, 1967). Precisamente allí radica un valor de la perversión: su capacidad para poner en cuestión al padre. Como lo dice Jean-Pierre Lebrun (2015), "para tomar en cuenta que más allá de su efecto mortificante, las palabras deben siempre estar el servicio de lo vivo. Una manera de prevenir el riesgo de volver a una religión de lo simbólico" (p. 336). Por ello resulta preocupante cuando, incluso el día de hoy, ciertos colegas hacen del masoquismo una entidad clínica que no logra distinguirse del sadismo - insistiendo en una unidad sadomasoquista (Gabbard, 2012; Holtzman \& Kulish, 2012) - de la automutilación, del autosabotaje o de determinadas prácticas sexuales. Véase, por ejemplo, el caso de Otto Kernberg (2012) quien señala que podemos encontrarnos con un masoquismo psicótico, un masoquismo narcisista, o un masoquismo neurótico, borrando así todo el complejo desarrollo de la empresa masoquista. De allí entonces que nos apropiamos de la invitación de Deleuze (1967) quien nos dice

Hay que recomenzar todo, y recomenzar por la lectura de Sade y de Masoch. Puesto que el juicio clínico está lleno de prejuicios, hay que recomenzar todo en un punto situado fuera de la clínica, el punto literario, a partir del cual las perversiones fueron nombradas. (p. 11)

Se trata de reconocer el valor literario, el proyecto estético y la sintomatología que se cristaliza a partir de estos dos autores que dan origen a las categorías clínicas mediante la antonomasia. Si somos realmente respetuosos de estos proyectos y procuramos esclarecer los mecanismos específicos que se ponen en marcha en cada uno de estos proyectos, estaremos quizás en posición de aprehender los alcances y límites que nos propone la perversión. 


\section{Referencias}

Assoun, P-L. (2003). Leçons psychanalytiques sur le masochisme. París, FR: Anthropos.

Deleuze, G. (1967). Présentation de Sacher-Masoch. París, FR: Les éditions de Minuit.

De Sacher-Masoch, W. (1989). Confession de ma vie. París, FR: Gallimard.

Freud, S. (2013a). Sobre la más generalizada degradación de la vida amorosa (Contribuciones a la psicología del amor, II). In Sigmund Freud Obras Completas (Vol. XI, pp. 169-184). Buenos Aires, AR: Amorrortu. (Trabajo original publicado en 1912).

Freud, S. (2013b). Introducción al narcisismo. In Sigmund Freud Obras Completas (Vol. XIV, pp. 65-98). Buenos Aires, AR: Amorrortu. (Trabajo original publicado en 1914).

Freud, S. (2013c). Pulsión y destinos de pulsión. In Sigmund Freud Obras Completas (Vol. XIV, pp. 105-134). Buenos Aires, AR: Amorrortu. (Trabajo original publicado en 1914).

Freud, S. (2013d). Más allá del principio del placer. In Sigmund Freud Obras Completas (Vol. XVIII, pp. 1-62). Buenos Aires, AR: Amorrortu. (Trabajo original publicado en 1920).

Freud, S. (2013e). Psicología de las masas y análisis del yo. In Sigmund Freud Obras Completas (Vol. XVIII, pp. 63-136). Buenos Aires, AR: Amorrortu. (Trabajo original publicado en 1921).

Freud, S. (2013f). El problema económico del masoquismo. In Sigmund Freud Obras Completas (Vol. XIX, pp..161-176). Buenos Aires, AR: Amorrortu. (Trabajo original publicado en 1924).

Freud, S. (2013g). El fetichismo. In Sigmund Freud Obras Completas (Vol. XXI, pp. 141-152). Buenos Aires, AR: Amorrortu. (Trabajo original publicado en 1927).

Foucault, M. (1976). Histoire de la sexualité I - La volonté de savoir. París, FR: Gallimard.

Gabbard, G. (2012). Masochism as a multiply-determined phenomenon. In D. Holtzman, N. \& Kulish (Eds.), The clinical problem of masochism (pp. 103-112). Lanham, MD: Jason Aronson.

Holtzman, D., \& Kulish, N. (2012). Introduction. In D. Holtzman \& N. Kulish (Eds.), The clinical problem of masochism (pp. 1-14). Lanham, MD: Jason Aronson.

Kernberg, O. (2012). Clinical constellations of masochistic psychopathology. In D. Holtzman, \& N. Kulish (Eds.), The clinical problem of masochism (pp. 15-28). Lanham, MD: Jason Aronson. 


\section{ARTIGOS}

Krafft-Ebing, R. (1895). Psychopatia Sexualis. Étude médico-légal. París, FR: Georges Carré.

Lacan, J. (1973). Le séminaire. Livre XI. Les quatres concepts fondamentaux de la psychanalyse. París, FR: Seuil. (Trabajo original publicado en 1964).

Lacan, J. (1994). Le séminaire. Livre IV. La relation d'objet. París, FR: Seuil. (Trabajo original publicado en 1956-57).

Lacan, J. (1998). Le séminaire. Livre V. Les formations de l'inconscient. París, FR: Seuil. (Trabajo original publicado en 1957-58).

Lacan, J. (1999a). Remarque sur le rapport de Daniel Lagache. In Écrits II (pp. 124162). París, FR: Seuil. (Trabalho original publicado em 1960).

Lacan, J. (1999b). Kant avec Sade. In Écrits II (pp. 243-272). París, FR: Seuil. (Trabalho original publicado em 1962).

Lacan, J. (2005a). Le séminaire. Livre X. L'angoisse. París, FR: Association Lacanienne Internationale. (Trabajo original publicado en 1962-63).

Lacan, J. (2005b). Le séminaire. Livre XIV. La logique du fantasme. París, FR: Association Lacanienne Internationale.(Trabajo original publicado en 1966-67).

Lacan, J. (2006). Le séminaire. Livre XVI. D'un Autre à l'autre. París, FR: Seuil. (Trabajo original publicado en 1968-69).

Lacan, J. (2013). Le séminaire. Livre VI. Le désir et son interprétation. París, FR: Éditions de La Martinière. (Trabajo original publicado en 1958-59).

Lebrun, J.-P. (2015). La perversion ordinaire. Paris, FR: Flammarion

Reyes, P. (2015). La notion de traumatisme dans l'enseignement de Jacques Lacan Logique du concept dans ses différentes versions (tesis doctoral). Université Paris VIII, Vincennes, Saint-Denis, París, FR.

Sacher-Masoch, L. (1967). La Vénus à la fourrure. In G. Deleuze, Présentation de Sacher-Masoch (pp. 117-248). París, FR: Les éditions de Minuit.

Sacher-Masoch, L. (1991a). La mère de Dieu. París, FR: Champ Vallon.

Sacher-Masoch, L. (1991b). L'amour de Platon. Lagrasse, FR: Verdier.

\section{Resúmenes}

(O fetichismo e a idealização como mecanismos de recuperação do gozo na cena masoquista. Observações psicopatológicas a partir do diálogo Lacan-Deleuze)

Este artigo visa fazer uma reflexão psicopatológica preliminar sobre a perversão masoquista baseada nas leituras de Jacques Lacan e Gilles Deleuze. Para isso, é preciso a premissa lacaniana de que o sujeito perverso procura interrogar 
e recuperar a parte de gozo subtraida para dar origem a um sujeito. Então, uma tentativa é feita para realizar essa premissa, assumindo dois aspectos fundamentais da encenação masoquista descrita por Deleuze: fetichismo e idealização. Finalmente, propõe-se que ambos os mecanismos, com o objetivo de cumprir tal empreendimento, busquem a produção de um objeto positivo na encenação masoquista.

Palavras-chave: Masoquismo, fetichismo, idealização, gozo

(Fetishism and idealization as jouissance recovery mechanisms in masochistic staging. Psychopathologic considerations based on the Lacan-Deleuze dialogue)

This article aims to make a preliminary psychopathological reflection on masochistic perversion based on the ideas of Jacques Lacan and Gilles Deleuze. To do so, it takes the Lacanian assumption according to which the perverse subject seeks to interrogate and recover the portion of the subtracted jouissance to make way to a subject. Then, an attempt is made to realize this assumption by taking back two fundamental aspects of the masochistic staging described by Deleuze: fetishism and idealization. Finally, it is proposed that both mechanisms seek the production of a positive object in the masochistic staging.

Key words: Masochism, fetishism, idealization, jouissance

(Le fétichisme et l'idéalisations comme mécanismes de récupération de jouissance dans la mise en scène masochiste. Remarques psychopathologiques à partir du dialogue Lacan-Deleuze)

Cet article a pour objectif de décrire une réflexion psychopathologique préliminaire sur la perversion masochiste à partir des lectures de Jacques Lacan et de Gilles Deleuze. Pour ce faire, nous partirons de la prémisse qui indique que le sujet pervers cherche à interroger et à récupérer le montant de jouissance soustrait pour qu'un sujet ait lieu. Ensuite, nous essayons de rendre compte de cette prémisse en reprenant deux aspect fondamentaux de la mise en scène masochiste décrite par Deleuze: le fétichisme et l'idéalisation. Finalement, nous proposons que ces deux mécanismes visent la production d'un objet positif dans la mise en scène afin d'achever la démarche masochiste.

Mots clés: Masochisme, fétichisme, idéalisation, jouissance 


\section{ARTIGOS}

Citação/Citation: Peña, F. D. (2021, set.). El fetichismo y la idealización como mecanismos de recuperación de goce en la puesta en escena masoquista. Consideraciones psicopatológicas a partir del diálogo Lacan-Deleuze. Revista Latinoamericana de Psicopatologia Fundamental, 24(3), 537-559. http://dx.doi.org/10.1590/1415-4714.2021v24n3p537.4.

Editora/Editor: Profa. Dra. Sonia Leite

Submetido/Submitted: 19.1.2020 / 1.19.2020 Revisado/Revised: 11.8 .2020 / 8.11.2020

Aceito/Acepted: $23.12 .2020 / 12.23 .2020$

Copyright: (C) 2009 Associação Universitária de Pesquisa em Psicopatologia Fundamental/ University Association for Research in Fundamental Psychopathology. Este é um artigo de livre acesso, que permite uso irrestrito, distribuição e reprodução em qualquer meio, desde que o autor e a fonte sejam citados / This is an open-access article, which permits unrestricted use, distribution, and reproduction in any medium, provided the original authors and sources are credited.

Financiamento/Funding: Este trabalho não recebeu apoio / This work received no funding.

Conflito de interesses/Conflict of interest: $\mathrm{O}$ autor declara que não há conflito de interesses. / The author declares that there is no conflict of interest.

Felipe Díaz Peña

Licenciado en Psicología y Psicólogo de la Universidad de Chile (Santiago de Chile); Doctorante de la Escuela Doctoral 450 Recherches en psychanalyse et psychopathologie de la Universidad de París, Ex-Universidad Paris 7 - Paris Diderot. (5 rue Thomas Mann, 75013, París, Francia); Psicólogo clínico en el servicio de psiquiatría infanto-juvenil del Hospital Simone Veil (agrupación hospitalaria Eaubonne-Monerency). Centro de día para el niño y el adolescente de Domont (2 rue des charpentiers, 95330, Domont, Francia).

24Ter rue Victor Hugo

94140 París, Francia

felipea.diazp@gmail.com

https://orcid.org/0000-0003-4573-9944

This is an open-access article, which permits unrestricted use, distribution, and reproduction in any medium for non-commercial purposes provided the original authors and sources are credited.

Rev. Latinoam. Psicopat. Fund., São Paulo, 24(3), 537-559, set. 2021 